\title{
Models of knot and stem development in black spruce trees indicate a shift in allocation priority to branches when growth is limited
}

Emmanuel Duchateau, David Auty, Frédéric Mothe, Fleur Longuetaud, Chhun Huor Ung, Alexis Achim

The branch autonomy principle, which states that the growth of individual branches can be predicted from their morphology and position in the forest canopy irrespective of the characteristics of the tree, has been used to simplify models of branch growth in trees. However, observed changes in allocation priority within trees towards branches growing in light-favoured conditions, referred to as 'Milton's Law of resource availability and allocation', have raised questions about the applicability of the branch autonomy principle. We present models linking knot ontogeny to the secondary growth of the main stem in black spruce (Picea mariana (Mill.) B.S.P.), which were used to assess the patterns of assimilate allocation over time, both within and between trees. Data describing the annual radial growth of 445 stem rings and the three-dimensional shape of 5377 knots were extracted from optical scans and X-ray computed tomography images taken along the stems of 10 trees. Total knot to stem area increment ratios (KSR) were calculated for each year of growth, and statistical models were developed to describe the annual development of knot diameter and curvature as a function of stem radial increment, total tree height, stem diameter, and the position of knots along an annual growth unit. KSR varied as a function of tree age and of the height to diameter ratio of the stem, a variable indicative of the competitive status of the tree. Simulations of the development of an individual knot showed that an increase in the stem radial growth rate was associated with an increase in the initial growth of the knot, but also with a shorter lifespan. Our results provide support for 'Milton's Law', since they indicate that allocation priority is given to locations where the potential return is the highest. The developed models provided realistic simulations of knot morphology within trees, which could be integrated into a functional-structural model of tree growth and above-ground resource partitioning. 
1 Title: Models of knot and stem development in black spruce trees indicate a shift in allocation

2 priority to branches when growth is limited

6 Authors: Emmanuel Duchateau ${ }^{1}$, David Auty ${ }^{1,2}$, Frédéric Mothe ${ }^{3}$, Fleur Longuetaud ${ }^{3}$, Chhun7 Huor $\mathrm{Ung}^{4}$, Alexis Achim ${ }^{1 *}$

$12{ }^{1}$ Renewable Materials Research Centre, Université Laval, 2425 rue de la Terrasse,

13 Québec G1V 0A6, QC, Canada

$14{ }^{2}$ Current address: Northern Arizona University, 200 East Pine Knoll Drive, Flagstaff, AZ

$15 \quad 86011-5018$

$16{ }^{3}$ AgroParisTech, UMR1092 LERFoB, 54000 Nancy, France

$17 \quad{ }^{4}$ Natural Resources Canada, Canadian Wood Fibre Centre, Laurentian Forestry Centre, $1055 \mathrm{du}$

18 P.E.P.S., P.O. Box 3800, Sainte-Foy, Quebec G1V 4C7

22 *For correspondence. Email: alexis.achim@sbf.ulaval.ca

23 


\section{Abstract}

3 The branch autonomy principle, which states that the growth of individual branches can be

4 predicted from their morphology and position in the forest canopy irrespective of the

5 characteristics of the tree, has been used in previous studies to simplify models of branch growth

6 in trees. However, observed changes in allocation priority within trees towards branches growing

7 in light-favoured conditions, referred to as 'Milton's Law of resource availability and allocation',

8 have raised questions about the applicability of the branch autonomy principle. We present

9 models linking knot ontogeny to the secondary growth of the main stem in black spruce (Picea

10 mariana (Mill.) B.S.P.), which were used to assess the patterns of assimilate allocation over

11 time, both within and between trees. Data describing the annual radial growth of 445 stem rings

12 and the three-dimensional shape of 5377 knots were extracted from optical scans and X-ray

13 computed tomography images taken along the stems of 10 trees. Total knot to stem area

14 increment ratios (KSR) were calculated for each year of growth, and statistical models were

15 developed to describe the annual development of knot diameter and trajectory as a function of

16 stem radial increment, total tree height, stem diameter, and the position of knots along an annual

17 growth unit. KSR varied as a function of tree age and of the height to diameter ratio of the stem,

18 a variable indicative of the competitive status of the tree. Simulations of the development of an

19 individual knot showed that an increase in the stem radial growth rate was associated with an

20 increase in the initial growth of the knot, but also with a shorter lifespan. Our results provide

21 support for 'Milton's Law', since they indicate that allocation priority is given to locations where

22 the potential return is the highest. The developed models provided realistic simulations of knot 
1 morphology within trees, which could be integrated into a functional-structural model of tree

2 growth and above-ground resource partitioning.

\section{Introduction}

4 Models of carbon assimilate allocation in trees generally consider branches to be part of either

5 the woody shoot or the crown (Landsberg and Waring 1997; Mathieu et al. 2009). However,

6 considering branch xylem as a separate sink can extend the practical applicability of functional-

7 structural tree models (FSTMs; Sievänen et al. 2000) to include wood properties considerations.

8 Knots are formed when branches are occluded by growing tree stems, and exert a strong

9 influence on the end-use characteristics of wood products (Buksnowitz et al. 2010).

11 Knot formation is driven by complex spatiotemporal interactions between a tree and its

12 environment. Thus, knowledge of the biological processes that regulate assimilate partitioning in

13 trees could improve models of branch growth. The branch autonomy principle (Van der Wal

14 1985; Sprugel and Hinckley 1988) has been used in some FSTMs to simplify the modelling process (Bosc 2000; Kull and Tulva 2000). The branch autonomy principle states that the growth

16 of individual branches can be predicted from their morphology and position in the forest canopy,

17 irrespective of tree characteristics. Models that incorporate this principle can also predict

18 mortality based on the growing space (Mitchell 1975) or the amount of light (Nikinmaa and Hari

19 1990) available to individual branches. However, there is an important limitation to this

20 principle. By comparing the height of the lower limit of the living crown in trees of different

21 sizes, Sprugel (2002) showed that branches on supressed trees were more likely to survive and

22 grow than the equivalent branches on dominant trees. This implied shift in allocation priority

23 within trees towards branches in light-favoured positions, referred to as 'Milton's Law of 
1 resource availability and allocation' (Sprugel 2002), suggests that assimilates are invested where

2 the potential return is highest. This is consistent with the results of Nikinmaa et al. (2003), who

3 obtained improved predictions of crown development when considering both the position and the

4 light environment of branches. However, experimental confirmation of Milton's Law is

5 generally restricted to static assessments of the location of the crown base in even-aged forest

6 stands (Valentine et al. 2013).

8 Branch ontogeny can be studied in long-term experiments (Pretzsch 2005), but repeated

9 measurements on the same trees are time-consuming and costly. One solution to this problem is

10 to use empirical branch distribution models to simulate the temporal development of tree and

11 branch growth using cross-sectional data i.e. observations of the number, location and size of

12 branches made on trees of different ages (Colin and Houllier 1991; Mäkinen and Mäkelä 2003;

13 Achim et al. 2006; Weiskittel et al. 2007). However, the simplicity of the approach comes at the

14 expense of reduced accuracy for some branch measurements (Duchateau et al. 2013a). More

15 recently, non-destructive techniques for rapidly generating high-resolution data have been

16 developed, such as infrared imaging, optical scanning, magnetic resonance imaging (MRI), and

17 computed tomography (CT) using X-rays or gamma rays (Moberg 2001; Longuetaud et al. 2012;

18 Dutilleul et al. 2014). These innovations allow the use of internal data to simultaneously

19 reconstruct stem and knot growth over time.

21 In this study we present models linking knot ontogeny to the secondary growth of the main stem

22 in black spruce (Picea mariana (Mill.) B.S.P.), a dominant species in the North American boreal

23 forest. We used data from high-resolution CT scans of tree stems to reconstruct the history of 
1 both stem and knot development, with the aim of developing models that would apply in an

2 FSTM framework. First, we tested the hypothesis that the ratio of branch to stem growth was

3 dependent on stem characteristics indicative of the competitive status of the tree. We then

4 developed statistical models for predicting the evolution of individual knot diameter and

5 trajectory using a series of predictors related to the position in the tree, stem radial growth, and

6 other general stem characteristics. This allowed us to test 'Milton's Law' using longitudinal data

7 i.e. repeated measurements of branch and stem growth over time. This approach allowed us to

8 make detailed simulations of knot development while considering the variation in assimilate

9 partitioning between trees.

\section{Materials and methods}

\section{Tree sampling}

13 Sample trees were collected from seven naturally-regenerated, unmanaged forest stands in the

14 North-Shore region of Quebec, Canada. All sampling locations were part of a network of sites

15 established to study the growth of spruce-moss forests after fire (Barrette et al. 2013; Torquato et

16 al. 2014; Ward et al. 2014). At the time these plots were established, efforts were made to

17 maintain site characteristics (i.e. surface deposit, topographic position, exposure and soil

18 drainage) as constant as possible and representative of mesic conditions (Ward et al. 2014).

20 Because CT-Scanning is costly and the associated data processing time-consuming, we worked

21 with a limited number of sample trees. In each of the seven stands, two trees were randomly

22 selected for destructive sampling. However, four trees were omitted from the analysis due to 
1 missing discs and the presence of wood decay. Of the ten trees in our final sample, eight came

2 from even-aged plots that had regenerated after fires dating back to between 66 and 152 years

3 (Bouchard et al. 2008). Two more trees (T09 and T10) were selected from one uneven-aged plot

4 where the time since the last stand-replacing fire exceeded 200 years. The sample trees had a

5 wide range of ages, crown size and stem dimensions (Table 1).

\section{Annual knot data}

After felling, each tree was cut into $2.5-\mathrm{m}$ logs, giving a total of 41 logs that were then transported to the Institut National de la Recherche Scientifique in Quebec City and scanned using a Somatom Sensation 64 CT scanner (Siemens Medical Solutions USA, Inc., Malvern, PA). Each log was scanned at 2-mm intervals along its longitudinal axis with a 2-mm-wide Xray beam $(120 \mathrm{kV}-50 \mathrm{~mA})$, so that the scanned segments were contiguous. The pixel size was $0.35 \mathrm{~mm} \times 0.35 \mathrm{~mm}$ in the transverse direction.

Knot geometry was extracted using the ImageJ 1.44 free software (Abramoff et al. 2004), with a Java plug-in ('Gourmand', version 1.01) developed at INRA, Nancy, France (Longuetaud et al.

17 2012). On successive images, the tangential limits of each knot were manually delineated with a series of points (Fig. 1A). A second purpose-built software named 'BIL3D' (Colin et al.

19 2010) was developed to visualise the position and 3D geometry of each knot using the Cartesian coordinates of each point (Fig. 1B). The series of points representing the tangential limits of the

21 knot were interpolated using spline curves. This allowed us to position the central axis (as the middle of both curves) and diameter (as the distance between each curve, assuming a circular cross section) of each knot from its point of origin to the bark. In a database, the diameter (D) of 
1 the knot was recorded at an interval of $1 \mathrm{~cm}$ from the stem's pith in the radial direction.

2 Similarly, the position of the central axis of the knot along the longitudinal stem axis (Z, referred

3 to as the 'trajectory') was recorded at an interval of $1 \mathrm{~cm}$ from the stem's pith. This way, we

4 obtained a representation of the geometric profiles of 5377 knots. A more detailed description of

5 the knot reconstruction method was presented by Duchateau et al. (2013a).

7 The demarcation between stem and knot xylem cannot be considered as perfectly discrete. Knot

8 profiles were therefore extracted from the $\mathrm{CT}$ images by manually delineating high density wood

9 corresponding to a knot and the surrounding lower density stem wood. Although the transition

10 was generally clear enough to ensure accuracy (Fig. 1), the knot reconstruction process produced

11 some localized irregularities that did not reflect the true shape of the knots. For this reason, we

12 chose to smooth the radial profiles of each knot using a combination of two Weibull equations,

13 which can reproduce a wide variety of knot profiles (Duchateau et al. 2013a). This also had for

14 advantage to provide a parametric description of each knot that was dependent on the radial

15 position within the stem. It is possible, however, that abrupt variations in knot shape were missed

16 due to the smoothing process.

17

18 Knot development at a given radial position $(l)$ was reconstructed using the diameter $\left(D_{1}\right)$ and 19 trajectory data $\left(Z_{1}\right)$. The same Weibull equation with an additional linear term was used to model 20 both series of $D_{1}$ and $Z_{1}$ measurements:

21

$22 y_{l}=\alpha\left(1-e^{\left.\left(-\beta\left(\frac{l}{R_{\max }-l}\right)\right)\right)}+\mu \cdot l \quad\left(0 \leq l<R_{\max }\right)\right.$ 
1 where $y_{1}$ represents either the $D_{1}$ or $Z_{1}$ values $(\mathrm{mm}), l$ is the distance from the stem's pith in the

2 radial direction $(\mathrm{mm}), \mathrm{R}_{\max }$ is the total length $(\mathrm{mm})$ of the knot along the stem's radial direction 3 and $\alpha, \beta$ and $\mu$ are parameters to be estimated empirically.

5 The functions were fitted to each knot independently using the $n l s$ function of the $n l m e$ library in

6 the R statistical programming environment (R Core Team, 2014). The models for both $\mathrm{D}_{1}$ and $\mathrm{Z}_{1}$

7 converged for $95 \%$ of the knots in the database. Visual examination revealed that non-

8 convergent knots were generally small and sinuous. Indeed, convergent knots represented 98\%

9 of the total volume of knots in the entire dataset, which we considered representative of the full 10 history of knot growth in our sample trees.

\section{Annual ring data from the main stem}

The model presented by Duchateau et al. (2013a) only made static predictions of knot shape

14 based on external branch characteristics. To meet the objective of this study to link knot ontogeny to the secondary growth of the main stem, it was necessary to reconstruct the yearly growth of the stem at its interface with each knot. Annual ring data from the main stem were

17 difficult to obtain from the $\mathrm{CT}$ images due to factors such as narrow rings and the higher moisture content of the sapwood. One-cm-thick discs were hence cut from the ends of each log

19 to reconstruct the growth history of the stems. Discs were optically scanned and annual ring boundaries were delineated in the four cardinal radial directions using image analysis software (WinDENDRO ${ }^{\mathrm{TM}}$; Régent Instruments, Quebec City, 2005; Guay et al. 1992). 
1 To link annual changes in knot geometry with stem radial increments, a first linear interpolation

2 was made, in each cardinal direction, between the widths of each matching ring from both ends

3 of each $\log$ (Fig. 2A). For rings present near the pith of the lower disc but absent from the upper

4 disc, we used the mean slope and intercept of linear interpolations derived for the first five

5 complete rings. This way, we obtained estimates of annual ring widths at any height along the

6 stem in the four main cardinal directions.

8 To obtain estimates of stem growth in the azimuthal direction of a knot (Fig. 2B), a second

9 interpolation was made from the two surrounding cardinal directions for which we had annual

10 ring width measurements. In this case we used a weighted average of the two known ring width

11 series located on each side of the knot. We defined $\alpha_{\mathrm{r}}$ as the azimuth angle between a knot and

12 one of the two cardinal directions on each side. The weighting factor was calculated as (90-

$\left.13 \alpha_{\mathrm{r}}\right) / 90$, which approached a value of 1 if the knot orientation was close to one of the two cardinal

14 directions. Due to irregularities in stem shape, the resulting series of stem rings associated with a

15 given knot did not end in the same exact location as the knot-stem interface, which was located

16 on the CT images. Therefore, a small correction constant was added (or subtracted) to each ring

17 in the series to ensure that both matched exactly. These linear interpolations of annual ring width

18 variation between two sample discs were a simplification, since in reality growth rings deviate

19 around knots (Pellicane and Franco 1994). However, given the imposibility to extract the

20 position of growth rings along each knot directly from CT images, this was considered as a good

21 approximation.

22

23 In a final step in the knot and stem growth reconstruction process, we traced back the annual

24 limits of primary growth. Each annual elongation of the shoot was defined as a growth unit 
1 (GU). Like other conifers, black spruce produces several nodal and internodal branches within a

2 growth unit. Nodal branches are those forming a whorl at the top of a GU (Achim et al. 2006,

3 Auty et al. 2012). Botanically, the branches of conifers do not technically originate from the

4 same vertical position, these are referred to as 'pseudo-whorls' (Fisher and Honda 1979).

5 However, this distinction was not apparent at the resolution of our CT-scanning measurements.

6 Therefore, we summed the basal areas of all branches that originated from the same CT image,

7 which facilitated the identification of pseudo-whorls of branches that were used as the limits of

8 annual GUs. To avoid large errors, we ensured that the number of GUs matched the difference in

9 the number of annual rings measured at both ends of each log. A more detailed description of the 10 growth unit identification method is presented in Duchateau et al. (2013b).

12 Once we had obtained a full description of both the knots and stem shape, a final step was to 13 obtain the annual increments in knot diameter $\left(\Delta \mathrm{D}_{\mathrm{t}}\right)$ and trajectory $\left(\Delta \mathrm{Z}_{\mathrm{t}}\right)$. These were computed 14 using the intersection points between stem rings and knots, and by considering the diameter 15 perpendicular to the central axis of the knot at each intersection point (Fig. 3)

\section{Model development}

\section{Tree-level models}

19 To examine the variation in biomass allocation between the stem and branches over time, the 20 ratio of knot to stem growth ( $\mathrm{KSR}_{\mathrm{i}, \mathrm{t}}$, dimensionless) was calculated, for each year of growth ( $\left.\mathrm{t}\right)$ in

21 a tree, as the sum of all knot area increments at the surface of the stem divided by the annual

22 basal area increment of the stem at $1.3 \mathrm{~m}$. Because the trees were not scanned all the way to the 23 stem apex, the most recent annual growth rings were incomplete. These were therefore omitted 
1 from the analysis so that calculations were made only for years where complete growth data

2 were available. When knots had reached a constant or decreasing diameter they were considered

3 to be dead.

4

5 To assess the variation of $\mathrm{KSR}_{\mathrm{i}, \mathrm{t}}$ through the life of the tree, we developed a linear mixed-effects

6 model (Pinheiro and Bates 2009) describing its evolution as a function of tree height-diameter

7 ratio and tree age. To assess the effect of within stand competition on $\mathrm{KSR}_{\mathrm{i}, \mathrm{t}}$, the ratio $\left(\mathrm{HD}_{\mathrm{i}, \mathrm{t}}\right.$,

$8 \mathrm{~m} / \mathrm{cm})$ between tree height $\left(\mathrm{H}_{\mathrm{i}, \mathrm{t}}\right)$ and its diameter at breast height $\left(\mathrm{DBH}_{\mathrm{i}, \mathrm{t}}\right.$, measured at $\left.1.3 \mathrm{~m}\right)$

9 was used as a surrogate for the competitive status of the subject trees at a given age. This ratio is

10 useful because inter-tree spacing is known to strongly affect crown development and hence the

11 radial growth of the stem, whereas it has much less effect on height growth (Weiskittel et al.

12 2011). Since values of $\mathrm{KSR}_{\mathrm{i}, \mathrm{t}}$ were continuous and non-negative, it was modelled as a gamma

13 distribution with a log-link:

14

$\llbracket \ln \left(K S R \rrbracket_{i, t}\right)=a_{1}+a_{\mathbf{2}} \cdot H D_{i, t}+a_{\mathbf{3}} \cdot A g e_{i, t}+\delta_{i}+\varepsilon$

16 where $\ln \left(\mathrm{KSR}_{\mathrm{i}, \mathrm{t}}\right)$ is the natural logarithm of the knot to stem ratio in a given year $\mathrm{t}, \mathrm{Age}_{\mathrm{i}, \mathrm{t}}$ is the

17 age of the tree (years), $a_{1}, a_{2}, a_{3}$ are the model parameters, $\delta_{i}$ is the random effect for each tree (i),

18 and $\varepsilon$ is the residual error of the model.

20 Next, we examined the effect of $\mathrm{KSR}_{\mathrm{it}}$ on the number of new branches produced in a given year

21 by fitting a Poisson regression model, with a log-link, describing the number of new branches

22 per stem as a function of $\mathrm{KSR}_{\mathrm{it}}$, tree age and their interaction: 
$\llbracket \ln \left(N B R \rrbracket_{i t}\right)=b_{\mathbf{1}}+b_{\mathbf{2}} \cdot K S R_{i t}+b_{3} \cdot A g e_{i t}+b_{4} \cdot K S R_{i t} \cdot A g e_{i t}+\delta_{i}+\varepsilon$

2 where $\ln \left(\mathrm{NBR}_{\mathrm{it}}\right)$ is the natural logarithm of the number of new branches per stem in a given year,

$3 b_{1}, b_{2}, b_{3}, b_{4}$ are the model parameters, and all other variables are as previously defined.

4

5 The models presented in equations 2 and 3 were fitted using the glmer function in the lme 4 library (Bates et al. 2014) of the R statistical programming environment (R Core Team 2014). In model fitting, we began by screening all potential tree-level explanatory variables and biologically plausible interaction terms. Variables were selected after calculating the variance inflation factors (VIF), to address any potential multicollinearity issues (O'brien 2007). Variables that were highly correlated (VIF $>4$ ) were excluded from the models. Variable selection for equations 2 and 3 was the result of a backwards elimination process in which the selection was based on Akaike's information criterion (AIC) (Akaike 1974). Chi-squared-based likelihood ratio tests were used to evaluate the significance of terms that were successively dropped from the model. In the absence of a significant difference $(p>0.05)$, the simplest model was retained. Parameter estimates were obtained using the maximum likelihood method.

\section{Individual knot models}

Next, statistical models were developed to describe the temporal evolution of the morphology of individual knots using annual ring- and tree-level characteristics as independent variables. Initially, we attempted to fit a single model describing both trajectory $\left(\mathrm{Z}_{\mathrm{i}, \mathrm{j}, \mathrm{t}}\right)$ and knot diameter $\left(D_{i, j, t}\right)$ simultaneously, thereby reconstructing the entire knot in a single step. However, this led to an underestimation of knot diameter in the first years of growth that carried over for the entire knot profile. Therefore, separate models were developed for each separate component. Individual 
1 knot diameter and trajectory models were fitted to the data from a random selection of $75 \%$ of

2 the total population of knots, while the remaining data were used for model evaluation.

\section{$4 \quad$ Knot diameter model}

5 We observed relatively consistent patterns in the diameter development of the knots. There was a

6 rapid increase in diameter increment in the first three years of knot growth, followed by a

7 gradual decline of growth until branch death (Fig. 4A). On average, branch increments reached

8 zero at around year 25 . We hence divided each diameter profile into three sections: 1) the

9 initiation section (years 0 to 3), 2) the growth section (years 4 to 25) and 3) the stable or

10 declining section (years $>25$ ). In the initiation section, because $\Delta \mathrm{D}_{\mathrm{i}, \mathrm{j}, \mathrm{t}}$ values did not follow a

11 Gaussian distribution, $\mathrm{D}_{\mathrm{i}, \mathrm{j}, \mathrm{t}}$ was modelled directly. In the remaining two sections $\Delta \mathrm{D}_{\mathrm{i}, \mathrm{j}, \mathrm{t}}$ was used 12 as the response variable.

13

14 Knot characteristics at time $t-1$ were used to make predictions at time $t$. This ensured a smooth

15 transition between the different sections of the model. After the variable selection process, the general form of the knot diameter model for each section was expressed as: 
1

2

$\Delta D_{i, j, t}$ or $D_{i, j, t}=c_{1}+c_{2} \cdot \Delta D_{i, j,(t-1)}+c_{3} \cdot D_{i, j, t-1}+c_{4} \cdot G U_{p o s} i, j+c_{5} * l_{i, j, t}+c_{6} \cdot R W_{i, j, t}+c_{7} * H D_{i, t}+c_{8} \cdot A g e_{i, t}+c_{9} \cdot D B H_{i, t}+c_{10} \cdot H_{i, j}+$

where $\mathrm{GU}_{\text {pos } \mathrm{i}, \mathrm{j}}$ is the relative position of the knot initiation point along the $\mathrm{GU}$ (varies from 0 at the base to 1 at the stem apex, and is used to take the phenomenon of acrotony (Powell 1995) into account), $\mathrm{RW}_{\mathrm{i}, \mathrm{j}, \mathrm{t}}$ is the ring width of the stem at the location of the knot in year $t, \delta_{\mathrm{i}}$ and $\delta_{\mathrm{i}, \mathrm{j}}$ are the tree- and knot-level random effects and $\varepsilon$ is the residual error. All other variables are as previously defined.

\section{Knot trajectory model}

The average annual variation of $\Delta \mathrm{Z}_{\mathrm{i}, \mathrm{j}, \mathrm{t}}$ was typically positive until approximately ring 40 . After this point the trajectory stabilized, before decreasing after ring 60 (Fig 4B). The knot trajectory profiles were therefore separated into two sections delineated at ring number 50. Characteristics of the knots in year $t$ - 1 were also included in this model, thus ensuring a smooth transition between the sections. Various combinations of the explanatory variables were used in each section of the model. The general form of the knot trajectory model for each section was expressed as:

$\Delta Z_{i, j, t}=d_{1}+d_{2} \cdot D_{i, j,(t-1)}+d_{3} \cdot \Delta Z_{i, j,(t-1)}+d_{4} * l_{i, j, t}+d_{5} \cdot R W_{i, j, t}+d_{6} \cdot G U_{p o s i, j}+d_{7} \cdot H D_{i, t}+d_{8} \cdot A g e_{i, t}+d_{9} \cdot D B H_{i, t}+\delta_{i}+\delta_{i, j}+\varepsilon$ (5)

where all variables are as previously defined. See Table 2 or a full description of all variable names used in the models.

These models were fitted using functions contained in the nlme library of the R statistical programming environment (R Core Team 2014). A power variance function of annual ring number from the pith at the level of each knot $(\mathrm{RN})$ was included to account for 
1 heteroscedasticity in the model residuals. In addition, a continuous first-order auto-regressive

2 term (AR1) was added to account for autocorrelation between successive measurements. The

3 model fitting process started by including a full set of potential ring-, knot- or tree-level

4 explanatory variables and model selection was performed using the same backwards elimination 5 procedure as described in the section on tree-level models.

Simulations

8 To analyse the influence of tree growth and competitive status on knot development, we

9 reconstructed a single knot at $6.1 \mathrm{~m}$ using the predictions from equations 4 and 5 and the stem 10 and growth characteristics of tree T10. Then, while keeping tree height constant, we increased

11 the annual ring increments by $50 \%$. The diameter and trajectory profiles of the original knot were

12 then recalculated. The process was repeated by decreasing the annual stem increments of the 13 same tree by $50 \%$ of their actual values and again predicting knot morphology.

In a second simulation, all knots from a $1.5-\mathrm{m}$ section starting at a height of $2.5 \mathrm{~m}$ in tree T4 were simulated using equations 4 and 5 and compared to the real knots, as extracted from the CT

17 images. For this simulation we used the known insertion points along the stem and azimuthal orientation of each knot. Where appropriate, the year at which a knot was observed to be completely occluded by the growing stem was used as the end-point of the simulation. 


\section{Results}

\section{Tree-level models}

3 The knot to stem increment ratio $\left(\mathrm{KSR}_{\mathrm{t}}\right)$ varied considerably with tree age. On average, $\mathrm{KSR}_{\mathrm{t}}$

4 was higher when trees were young and decreased rapidly in the first few years, before stabilizing

5 (Fig. 5). The rate of the initial decrease varied among trees. Values of $\mathrm{KSR}_{\mathrm{t}}$ greater than 1

6 indicated that, in a given year, the total knot basal area increment exceeded that of the stem. In

7 addition to the negative relationship with tree age, $\mathrm{KSR}_{\mathrm{t}}$ ratio was positively related to $\mathrm{HD}_{\mathrm{t}}$, such

8 that more slender trees allocated relatively more biomass to their branches than to the main stem

9 (Fig. 6). Furthermore, in a given year, the predicted number of new branches produced was

10 greater in trees with higher $\mathrm{KSR}_{\mathrm{t}}$ values, but the effect of $\mathrm{KSR}_{\mathrm{t}}$ decreased with increasing tree

11 age (equation 3; Table 3).

12

13 In some trees, KSR values showed large interannual fluctuations from the general trend (Fig. 5).

14 The 3D reconstructions of the stem and knots for two of these trees showed large deviations of

15 the pith of the main stem, likely a result of leader loss or stem damage. While one of these trees

16 retained apical dominance in a single leader (T01), the other produced a fork (T09; Fig. 7). The

17 model produced a good fit to all trees except tree T03, although visual examination of the 3D

18 reconstruction of this stem revealed no obvious explanation for the lack of fit. 


\section{$1 \quad$ Knot-level models}

2 Table 4 shows the fixed effects parameter estimates and standard errors for each section of the

3 final knot diameter model (equation 4). To evaluate the model, knot diameter profiles were

4 predicted and compared to observations in the evaluation dataset. Plots of the raw residuals

5 (observed minus predicted values) showed that, on average, knot diameter was slightly

6 underestimated in the middle section of the knot profiles, but overall the model was unbiased

7 (Fig. 8A). The mean absolute error was 0.031 and the root mean square error (RMSE) 0.054 .

8 When the profile of each knot in the database was reconstructed by adding successive annual

9 diameter predictions, the absolute value of $50 \%$ of the residuals was less than $2.6 \mathrm{~mm}$ along the

10 pith-to-bark profiles, while the absolute value of $90 \%$ of the residuals was less than $9.7 \mathrm{~mm}$.

12 Table 5 shows the fixed effects parameter estimates and associated standard errors for each

13 section of the final model of knot trajectory (equation 5). Again, predictions of knot trajectory

14 profiles were compared to observations in the evaluation dataset. On average, the model was

15 unbiased along the knot profile up to ring 75, with a slight overestimation beyond this point (Fig.

$168 \mathrm{~B}$ ). The mean absolute error for this model was 0.118 and the root mean square error (RMSE)

$17 \quad 0.189$. When the profile of each knot was reconstructed by adding successive annual trajectory

18 predictions, the absolute value of $50 \%$ of the residuals was less than $11.9 \mathrm{~mm}$ along the entire

19 pith-to-bark profiles, while the absolute value of $90 \%$ of the residuals was less than $36.7 \mathrm{~mm}$. 


\section{Simulations}

2 When we used the dimensions and growth of a real tree (T10) to simulate knot growth, the

3 diameter increments in the early years of knot development were positively related to the radial

4 growth of the main stem. However, knot longevity was reduced when the radial growth was

5 artificially increased (and thus the HD ratio decreased). Knot growth ceased at ring 19 for the

6 elevated growth scenario, but it was maintained along its entire profile (47 years) when stem

7 growth was reduced (Fig. 9). In the real growth scenario, knot diameter increments began to

8 decline around ring 25. Tree HD ratio also had a significant effect in the first section of the knot

9 trajectory model, although the effect was only apparent in the lower stem (not shown).

11 In the second simulation we reconstructed all knots in a 1.5-m section of tree T04. This showed

12 that although the diameter of larger knots was slightly underestimated, the models generally

13 produced accurate simulations of the diameter and shape of real knots. However, the models

14 produced less variation in knot insertion angle than was observed in reality (Fig. 10), which

15 would likely explain the larger residuals of the trajectory model.

\section{Discussion}

\section{Resource allocation}

19 This study provides further support to the idea that allocation of above-ground carbon assimilates

20 in trees is directed towards locations where the potential return is the highest (Sprugel 2002). To

21 maintain a favourable position in the canopy, trees subjected to high levels of competition

22 prioritize height growth over secondary radial growth (Lanner 1985). Consequently, at a given 
1 age, the HD ratio is a useful predictor of assimilate partitioning among tree organs (West 1993;

2 King 2005; McCarthy and Enquist 2007). Despite large variation in annual knot growth, even

3 among similar sized trees, the ratio of knot to stem area increment (KSR) was shown to decrease

4 systematically with tree age. Similar ontogenetic effects have been highlighted by Wilson (1988)

5 to describe changes in shoot : root ratio as a plant grows.

7 Under the assumption that stem or branch area increments are proportional to biomass

8 accumulation, the observed correlation between KSR and HD indicates a shift in assimilate

9 allocation towards branches when tree growth is constrained by competition. Likewise, Vincent

10 (2006) found that lower light levels were associated with an increase in leaf life span, while King

11 (1997) showed that the percentage of biomass allocated to branches was higher in understory

12 seedlings than in those growing in large gaps. A similar concept of functional balance has also

13 been used to explain the decrease in shoot : root ratio when soil nutrients are a limiting factor

14 (Génard et al. 2007). Under the principles of teleonomy, these may be seen as adaptive responses

15 of trees to environmental factors, which would optimize their growth and survival probability

16 (Lacointe 2000).

18 In this study, annual reconstructions of stem and branch development suggested that KSR values 19 were also positively related to the number of new branches initiated in a growth unit. This is in 20 agreement with the principles highlighted above, but it appears to contradict a common result of 21 empirical branch distribution models, which is that vigorous trees tend to initiate more branches 22 in a given year (Maguire 1994; Mäkinen and Colin 1999; Hein et al. 2007). However, these 23 studies typically presented models for the number of nodal branches i.e. those forming a pseudo- 
1 whorl (Fisher and Honda 1979). Furthermore, in models that consider both nodal and internodal

2 branches, smaller branches $(<5 \mathrm{~mm})$ are usually ignored (Colin and Houllier 1991; Auty et al.

3 2012). An advantage of using CT scanning technology is that all the knots were identifiable,

4 including those that were occluded within the stems. Furthermore, the identification of annual

5 growth units along the stem was made easier because it was possible to locate, with some

6 certainty, the initiation point of branches at the stem's pith (Duchateau et al. 2013b).

8 The relationship of knot growth to HD ratio could be clearly seen in the simulations of individual

9 knot growth. An increase in HD ratio led to smaller but longer-lived knots. When coupled with our finding on branch initiation, this result is in agreement with the negative relationship

11 between the number of branches and their size presented by West et al. (2009). Throughout the 12 simulation, each knot was first located at the top of the stem but its position relative to the stem's

13 apex shifted as the tree grew in height. Therefore, in the slower growth scenario, the fact that the 14 knot was still growing at the end of the simulation implies a slower rate of crown recession. A

15 lower crown base in trees subject to high competition is consistent with previous results (Sprugel 16 2002; Valentine et al. 2013) and offers further support for Milton's Law of resource availability 17 and allocation. Sprugel's (2002) choice of name for this principle made reference to poet John 18 Milton's (1667) phrase, "Better to reign in hell than serve in heaven". He used this analogy to 19 highlight the fact that although branches in light-favored conditions will tend to grow faster, a 20 shaded branch on a shaded tree is more likely to survive and grow than a similarly-shaded branch 21 on a dominant tree. Our model provides a time-series illustration of this principle. The vigorous 22 growth of the knot in the first 10 to 15 years of the accelerated growth scenario suggests that the 23 carbon budget of the branch was more positive than branches simulated in slow growth 
1 scenarios. Despite this, branch growth ceased earlier in the accelerated growth scenario. Clearly,

2 such behaviour could not be predicted based on individual branch carbon budgets, which leads

3 us to question the applicability of the branch autonomy principle when modelling branch growth.

\section{$5 \quad$ Modelling knot development}

6 Previous studies have represented the dead portion of knots as a cylinder to reflect the cessation

7 of growth (Björklund 1997; Lemieux et al. 2001; Moberg 2001). However, around 40\% of knots

8 in our sample data had declining diameter profiles in the outer stem, presumably as a result of

9 branch deterioration after death. We accounted for this trend in the knot diameter model by

10 allowing negative growth predictions (Fig. 9). The inclusion of the diameter and trajectory

11 increments of the previous year as predictor variables allowed for smooth transitions between the

12 knot sections, which provided realistic knot shapes. Furthermore, analysis of the model residuals

13 showed that the models were relatively unbiased and generally accurate.

In the second simulation, annual predictions of knot diameter and trajectory produced realistic reconstructions of the real knot profiles using the known insertion point, orientation and year of

17 occlusion of each knot. Models that can predict the vertical and azimuthal distribution of

18 branches within a growth unit, as well as the initial insertion angle of each branch in the main

19 stem, will provide even more realistic stem profiles. Even further improvements could be gained

20 from the addition of a self-pruning sub-model (Mäkelä and Mäkinen 2003).

22 The interpretation of our results on knot and stem allocation should therefore focus on general,

23 long-term trends rather than on inter-annual variation. In fact, the long-term trends presented at 
1 the stem level should be more robust, since they aggregate information from a large number of

2 individual knot profiles.

\section{Conclusion}

5 This study has provided an improved representation of the internal structure of tree stems by

6 linking knot development with stem growth. The use of CT scanning data allowed us to

7 reconstruct knot and stem ontogeny with unprecedented detail over a substantial time period. We

8 have found evidence for increased allocation to branches under conditions that limit the

9 secondary growth of the stem, which indicates that branches are non-autonomous entities. We

10 have also produced a model of individual knot morphology that could provide greater precision

11 in the representation of knots in FSTMs, thus expanding their applicability to the wood

12 processing sector.

\section{Acknowledgements}

15 The authors are grateful to the Natural Sciences and Engineering Research Council of Canada

16 (NSERC) for the financial support for this project through the ForValueNet strategic research

17 network on forest management for value-added products. We are also grateful to Amélie

18 Denoncourt, Louis Gauthier, Fabien Lanteigne, Vanessa Joly, Alice Bernier Banville, Eugénie

19 Arsenault, and Caroline Hamelin for their assistance in collecting the samples. Two anonymous

20 reviewers provided helpful comments on an earlier version of the manuscript. The UMR 1092

21 LERFoB is supported by the French National Research Agency through the Laboratory of

22 Excellence ARBRE (ANR-12- LABXARBRE-01). 


\section{Literature cited}

3 Abramoff MD, Magalhaes PJ, Ram SJ. 2004. Image processing with ImageJ. Biophotonics International 11: $36-43$.

Achim A, Gardiner B, Leban J, Daquitaine R. 2006. Predicting the branching properties of Sitka spruce grown in

5 Great Britain. New Zealand Journal of Forestry Science 36: 246-264.

Akaike H. 1974. A new look at the statistical model identification. IEEE Trans Autom Control 19: 716-723.

Auty D, Weiskittel AR, Achim A, Moore JR, Gardiner BA. 2012. Influence of early re-spacing on Sitka spruce branch structure. Annals of Forest Science 69: 1-12.

Barrette J, Pothier D, Ward C. 2013. Temporal changes in stem decay and dead and sound wood volumes in the northeastern Canadian boreal forest. Canadian Journal of Forest Research 43: 234-244.

Bates D, Maechler M, Bolker BM and Walker S. 2014. "Ime4: Linear mixed-effects models using Eigen and S4." ArXiv e-print; submitted to Journal of Statistical Software, <URL:http://arxiv.org/abs/1406.5823>.

Björklund L. 1997. The interior knot structure of Pinus sylvestris stems. Scandinavian Journal of Forest Research 12: 403-412.

Bosc A. 2000. EMILION, a tree functional-structural model: Presentation and first application to the analysis of branch carbon balance. Annals of Forest Science 57: 555-569.

17 Bouchard M, Pothier D, Gauthier S. 2008. Fire return intervals and tree species succession in the North Shore region of eastern Quebec. Canadian Journal of Forest Research 38: 1621-1633.

Buksnowitz C, Hackspiel C, Hofstetter K, Muller U, Gindl W, Teischinger A, Konnerth J. 2010. Knots in trees: strain distribution in a naturally optimised structure. Wood Science and Technology 44: 389-398.

Colin F, Houllier F. 1991. Branchiness of Norway spruce in north-eastern France - Modeling vertical trends in maximum nodal branch size. Annales Des Sciences Forestieres 48: 679-693.

23 Colin F, Mothe F, Freyburger C, Morisset J-B, Leban J-M, Fontaine F. 2010. Tracking rameal traces in sessile 24 oak trunks with X-ray computer tomography: biological bases, preliminary results and perspectives. Trees 24: 953967.

Dinwoodie JM. 2000. Timber: Its nature and behaviour. Taylor \& Francis. 
1 Duchateau E, Auty D, Mothe F, Achim A. 2013b. Improving branch distribution models in trees using X-ray

2 computed tomography. 7th International Conference on Functional-Structural Plant Models, Saariselkä, Finland.

3 Saariselkä, Finland. http://www.metal.fi/fspm2013/proceedings. ISBN 978-951-651-408-9

4 Dutilleul P, Han LW, Beaulieu J. 2014. How do trees grow? Response from the graphical and quantitative analyses

5 of computed tomography scanning data collected on stem sections. Comptes rendus biologies 337: 391-8.

6 Fisher JB, Honda H. 1979. Branch geometry and effective leaf area: a study of Terminalia-branching pattern. 1.

7 Theoretical trees. American Journal of Botany 66 : 633-644.

Génard M, Dauzat J, Franck N, Lescourret F, Moitrier N, Vaast P, Vercambre G. 2007. Carbon allocation in fruit trees: from theory to modelling. Trees 22: 269-282.

Guay R, Gagnon R, Morin H. 1992. A new automatic and interactive tree ring measurement system based on a line scan camera. The Forestry Chronicle 68: 138-141.

12 Hein S, Mäkinen H, Yue CF, Kohnle U. 2007. Modelling branch characteristics of Norway spruce from wide 13 spacings in Germany. Forest Ecology and Management 242: 155-164.

King D a. 1997. Branch growth and biomass allocation in Abies amabilis saplings in contrasting light environments.

15 Tree physiology 17: 251-258.

King D a. 2005. Linking tree form, allocation and growth with an allometrically explicit model. Ecological Modelling 185: 77-91.

Kull 0, Tulva I. 2000. Modelling canopy growth and steady-state leaf area index in an aspen stand. Annals of Forest Science 57: 611-621.

Lacointe A. 2000. Carbon allocation among tree organs: A review of basic processes and representation in functional-structural tree models. Annals of Forest Science 57: 521-533.

Landsberg JJ, Waring RH. 1997. A generalised model of forest productivity using simplified concepts of radiationuse efficiency, carbon balance and partitioning. Forest Ecology and Management 95: 209-228.

Lanner RM. 1985. On the insensitivity of height growth to spacing. Forest Ecology and Management 13: 143-148.

Lemieux H, Beaudoin M, Zhang SY. 2001. Characterization and modeling of knots in black spruce (Picea mariana) logs. Wood and Fiber Science 33: 465-475.

Longuetaud F, Mothe F, Kerautret B, Krähenbühl A, Hory L, Leban JM, Debled-Rennesson I. 2012. Automatic knot detection and measurements from X-ray CT images of wood: A review and validation of an improved algorithm on softwood samples. Computers and Electronics in Agriculture 85: 77-89.

Maguire DA. 1994. Branch mortality and potential litterfall from Douglas-Fir trees in stands of varying density. Forest Ecology and Management 70: 41-53.

Mäkelä A, Mäkinen H. 2003. Generating 3D sawlogs with a process-based growth model. Forest Ecology and Management 184: 337-354. 
1 Mäkinen H, Colin F. 1999. Predicting the number, death, and self-pruning of branches in Scots pine. Canadian

2 Journal of Forest Research 29: 1225-1236.

3 Mäkinen H, Mäkelä A. 2003. Predicting basal area of Scots pine branches. Forest Ecology and Management 179:

$4 \quad 351-362$.

5 Mathieu A, Cournede PH, Letort V, Barthelemy D, de Reffye P. 2009. A dynamic model of plant growth with 6 interactions between development and functional mechanisms to study plant structural plasticity related to trophic 7 competition. Annals of Botany 103: 1173-1186.

McCarthy MC, Enquist BJ 2007. Consistency between an allometric approach and optimal partitioning theory in global patterns of plant biomass allocation. Functional Ecology, 21(4), 713-720.

10 Milton J. 1667. Paradise Lost. Peter Parker, London, 368 p.

11 Mitchell KJ. 1975. Dynamics and Simulated Yieldof Douglas-fir. Forest Science: a0001-z0001.

Moberg L. 2001. Models of internal knot properties for Picea abies. Forest Ecology and Management 147: 123-138.

Mothe F. 2014. http://www6.nancy.inra.fr/foret-bois-lerfob/Zoom-sur/Outils-pour-le-traitement-d-

Nikinmaa E, Hari P. 1990. A simplified carbon partitioning model for Scots pine to address the effects of altered needle longevity and nutrient uptake on stand development. In: Dixon R, Meldahl R, RUARK G, Warren W, eds. Process modeling of forest growth responses of environmental stress. Portland, USA: Timber Press Inc, 263-270.

Nikinmaa E, Messier C, Sievänen R, Perttunen J, Lehtonen M. 2003. Shoot growth and crown development: effect of crown position in three-dimensional simulations. Tree physiology 23: 129-36.

O'brien RM. 2007. A Caution Regarding Rules of Thumb for Variance Inflation Factors. Quality \& Quantity 41: 673690.

Pellicane PJ, Franco N. 1994. Modeling wood pole failure. Wood Science and Technology 28: 261-274.

Pinheiro JC, Bates DM. 2009. Mixed-effects models in S and S-PLUS. Springer.

Powell GR. 1995. The role of acrotony in reproductive development in Picea. Tree Physiology 15: 491-498.

Pretzsch H. 2005. Diversity and productivity in forests: evidence from long-term experimental plots. Forest diversity and function. Springer, 41-64.

R Core Team 2014. R: A language and environment for statistical computing. R Foundation for Statistical

30 Sievänen, R., Nikinmaa, E., Nygren, P., Ozier-Lafontaine, H., Perttunen, J., Hakula, H., 2000. Components of 31 functional-structural tree models. Ann. For. Sci. 57, 399-412.

32 Sprugel DG. 2002. When branch autonomy fails: Milton's Law of resource availability and allocation. Tree 33 Physiology 22: 1119-1124. 
1 Sprugel DG, Hinckley TM. 1988. The branch autonomy concept. Response of trees to air pollution: The Role of

2 Branch Studies. In: Winner W.E. \& Phelps L.G. E, ed. Proc. Workshop National Forest Response Program.7-23.

3 Torquato LP, Auty D, Hernández RE, Duchesne I, Pothier D, Achim A. 2014. Black spruce trees from fire-origin

4 stands have higher wood mechanical properties than those from older, irregular stands 1. 10: 1-10.

5 Valentine HT, Amateis RL, Gove JH, Mäkelä A. 2013. Crown-rise and crown-length dynamics: application to 6 loblolly pine. Forestry 86: 371-375.

7 Vincent G. 2006. Leaf life span plasticity in tropical seedlings grown under contrasting light regimes. Annals of 8 Botany $97: 245-55$.

9 Van der Wal DW. 1985. A proposed concept of branch autonomy and non-ring production in branches of Douglas-fir and grand fir. (Doctoral dissertation, University of Washington).

11 Ward C, Pothier D, Paré D. 2014. Do Boreal Forests Need Fire Disturbance to Maintain Productivity? Ecosystems

12 17: 1053-1067.

Weiskittel AR, Hann DW, Kershaw Jr JA., Vanclay JK. 2011. Forest Growth and Yield Modeling. Chichester, UK:

14 John Wiley \& Sons, Ltd.

15 Weiskittel AR, Maguire DA, Monserud RA. 2007. Response of branch growth and mortality to silvicultural treatments in coastal Douglas-fir plantations: Implications for predicting tree growth. Forest Ecology and Management 251: 182-194.

West PW. 1993. Model of above-ground assimilate partitioning and growth of individual trees in even-aged forest monoculture. Journal of Thoeretical Biology 161: 369-394.

20 West GB, Enquist BJ, and Brown JH. 2009. A general quantitative theory of forest structure and dynamics.

21 Proceedings of the National Academy of Sciences, 106 (17), 7040-7045.

22 Wilson JB. 1988. A review of evidence on the control of shoot : root ratio, in relation to models. Annals of Botany 61 : $23 \quad 433-449$. 


\section{Table Captions}

3 Table 1 Characteristics of the 10 sample trees in the dataset.

4 * The base of the crown was defined as the location of the lowest pseudo-whorl containing at least one live branch, 5 and above which all pseudo-whorls also contained at least one live branch

7 Table 2 Definitions and abbreviations of the variables used in this paper

8 Table 3 Fixed effects parameter estimates and standard errors of the KSR model given by 9 equation (2) and the model for the number of new branches given by equation (3).

11 Table 4 Fixed effects parameter estimates and standard errors for each section of the knot

12 diameter model given by equation (4). Section 1: knot initiation (1 to 3 years), Section 2: growth

13 phase (4 to 25 years), Section 3: stabilisation and death ( $>25$ years). Section 1 predicts the

14 diameter and sections 2 and 3 predict the diameter increment.

15

Table 5 Fixed effects parameter estimates and standard errors for each section of the knot

17 trajectory model given by equation (5). Section 1: typically increasing trajectory (years 0 to 50 ),

18 Section 2: typically decreasing trajectory (years $>50$ ). 


\section{Captions for figures}

3

4 Fig. 1 The knot extraction process. A) Extraction of the position and diameter of each knot

5 profile on CT scanning images using the ImageJ Java plug-in 'Gourmand' and B) reconstruction

6 of the 3D geometry of each knot using the software "Bil3D"

7

8 Fig. 2 Inferring ring width at the location of a knot: A) interpolation of the rings between the two

9 discs to reconstruct the $\log$ and $\mathbf{B})$ selection of the two cardinal directions bordering the knot to

10 reconstruct the ring widths along the knot profile.

11

12 Fig. 3 Inferring knot annual increments: A) example of ring width deformations around a knot;

B) extraction of the annual knot data.

14

15 Fig. 4 Distributions of annual increments in diameter $\left(\Delta D_{t}\right)$ and trajectory $\left(\Delta Z_{t}\right)$ of the knot

16 against annual ring number from the stem's pith. The grey line indicates the median of all

17 observations for a given ring number. Contours provide the distribution quantiles around the 18 median

20 Fig. 5 Scatterplots showing the evolution of KSR (total annual knot area increment/stem

21 increment at $1.3 \mathrm{~m}$ ) with tree age. Time series do not start at age 0 because $\mathrm{HD}_{\mathrm{t}}$ assessments start

22 when the stem has reached a height of $1.3 \mathrm{~m}$. Points $=$ observed values; red lines $=$ model 
1 predictions (Equation 2; Table 3). Horizontal red line shows an equality between the total annual

2 knot increment and the stem increment at $1.3 \mathrm{~m}(\mathrm{KSR}=1)$.

4 Fig. 6. Scatterplots of observed $\mathrm{KSR}_{\mathrm{t}} \mathrm{vs.} \mathrm{HD}_{\mathrm{t}}$ in each sample tree for cambial ages 5, 15, 25 and

535 at breast height. The linear regressions fitted though the points show a positive correlation

6 between the two variables for all ages. The shaded areas represent the standard errors.

8 Fig. 7. 3D reconstruction of sections of two stems showing deviation of the pith related to 9 possible stem breakage

11 Fig. 8 Distribution of the residuals (sorted by quantiles) against ring number when the model was 12 applied to the evaluation dataset. A) Knot diameter (Equation 4, Table 4) and B) knot vertical 13 position (Equation 5, Table 5). The grey line indicates the median of all observations for a given 14 ring number. Contours provide the distribution around the median.

16 Fig. 9 Simulations of a single knot from equations (4) and (5) at $6.1 \mathrm{~m}$ of the main stem. Stem 17 increments of tree T10 were used as the reference level for input parameters. A) Radial growth 18 decreased by $50 \%$; B) Reference level and C) Radial growth increased by 50\%. Real height 19 growth from tree T10 was used for all simulations. The knot was assumed to have died when 20 diameter increments reached zero. Red: live section; Blue: dead section. 
1 Fig. 10 Reconstruction of a 1.5-m section from the base of the second $\log$ of tree T04 (i.e. at 2.5

$2 \mathrm{~m}$ from the tree base). A) Real knots extracted using the CT scanning data. B) Simulated knots 3 using the known insertion point, azimuthal orientation around the stem, and year of occlusion. 


\section{Table $\mathbf{1}$ (on next page)}

Characteristics of the 10 sample trees in the dataset

The base of the crown was defined as the location of the lowest pseudo-whorl containing at least one live branch, above which all pseudo-whorls contained at least one live branch 


\begin{tabular}{lcccccc}
\cline { 2 - 6 } & Age & $\begin{array}{c}\text { Number of } \\
\text { complete rings } \\
\text { used on the } \\
\text { analysis }\end{array}$ & $\begin{array}{c}\text { Total Height } \\
(\mathbf{m})\end{array}$ & $\begin{array}{c}\text { Diameter at } \\
\text { breast height } \\
(\mathbf{c m})\end{array}$ & $\begin{array}{c}\text { Length of } \\
\text { the } \text { crown }^{*} \\
(\mathbf{m})\end{array}$ & $\begin{array}{c}\text { Number of } \\
\text { measured } \\
\text { knots }\end{array}$ \\
\hline T01 & 82 & 14 & 14.02 & 15.4 & 5.04 & 726 \\
T02 & 85 & 19 & 14.15 & 14.1 & 4.3 & 620 \\
T03 & 86 & 27 & 15.27 & 15.6 & 4.8 & 819 \\
T04 & 93 & 32 & 11.81 & 14.3 & 2.09 & 568 \\
T05 & 104 & 45 & 14.22 & 16.3 & 5.32 & 1066 \\
T06 & 106 & 47 & 20.52 & 22.2 & 8.77 & 1198 \\
T07 & 113 & 48 & 18.2 & 21.4 & 5.82 & 514 \\
T08 & 118 & 51 & 16.92 & 21.8 & 8.32 & 1121 \\
T09 & 139 & 78 & 16.28 & 17.8 & 5.42 & 993 \\
T10 & 152 & 84 & 20.8 & 22.4 & 5.25 & 1518 \\
\hline & 107.8 & 68.5 & 16.219 & 18.13 & 5.513 & 914.3 \\
mean & 23.47 & 24.36 & 2.93 & 3.45 & 1.90 & 321.14 \\
\hline sd & & & & & & \\
\hline
\end{tabular}


Table 2 (on next page)

Definitions and abbreviations of the variables used in this paper 


\section{Description}

\section{Tree-level variables}

$\mathrm{DBH}_{t}$

Age $_{t}$

$\mathrm{HD}_{\mathrm{t}}$

$\mathrm{KSR}_{\mathrm{t}}$
Diameter of the tree at $1.3 \mathrm{~m}$ at time $t(\mathrm{~mm})$

Age of the tree at time $t$

Ratio of total tree height to DBH calculated for each year of growth at time $t$

Ratio of total knot area increment to the stem basal area increment at time $t$

\section{Ring-level variables}

RN

$\mathrm{RW}_{\mathrm{t}}$

$1_{, \mathrm{t}}$

$\mathrm{GU}_{\mathrm{pos}}$

$\mathrm{H}_{\mathrm{k}}$
Annual ring number from the pith of the main stem at the level of each knot

Annual ring width at time $\mathrm{t}(\mathrm{mm})$

Distance from the pith of the stem at time $t(\mathrm{~mm})$

Relative position of the knot initiation point along the annual growth unit (varies from 0 to 1 )

Position of the initiation point of the knot along the stem (ground level $=0)(\mathrm{m})$

Knot-level variables

$\Delta \mathrm{D}_{\mathrm{t}}$

$\mathrm{D}_{\mathrm{t}}$

$\Delta \mathrm{Z}_{\mathrm{t}}$
Annual increment of the knot diameter from time t-1 to $\mathrm{t}(\mathrm{mm})$

Predicted knot diameter at time $\mathrm{t}(\mathrm{mm})$

Annual increment of the trajectory of the knot from time $\mathrm{t}-1$ to $\mathrm{t}(\mathrm{mm})$ 
Table 3(on next page)

Fixed effects parameter estimates and standard errors of the KSR model given by equation (2) and the model for the number of new branches given by equation (3). 
2

\begin{tabular}{ccrrr}
\hline Model & Parameter & Estimate & S.E. & $P$-value \\
\hline \multirow{3}{*}{ equation (2) } & a1 & -0.3956 & 0.11947 & $<0.0001$ \\
& a2 & 4.1717 & 0.23896 & $<0.0001$ \\
& a3 & -0.0114 & 0.00169 & $<0.0001$ \\
\hline \multirow{4}{*}{ equation (3) } & b1 & 1.7864 & 0.15040 & $<0.0001$ \\
& b2 & 0.0354 & 0.00934 & $<0.0001$ \\
& b3 & 0.0153 & 0.00105 & $<0.0001$ \\
& b4 & -0.0006 & 0.00024 & $<0.0001$ \\
\hline
\end{tabular}

3

4 
Table 4(on next page)

Fixed effects parameter estimates and standard errors for each section of the knot diameter model given by equation (4)

Section 1: knot initiation (1 to 3 years), Section 2: growth phase (4 to 25 years), Section 3:

stabilisation and death (>25 years). Section 1 predicts the diameter and sections 2 and 3 predict the diameter increment 


\begin{tabular}{|c|c|c|c|c|c|c|c|c|c|}
\hline \multirow[b]{2}{*}{ Parameter } & \multirow[b]{2}{*}{ Estimate } & \multicolumn{2}{|c|}{ Section 1} & \multicolumn{3}{|c|}{ Section 2} & \multicolumn{3}{|c|}{ Section 3} \\
\hline & & S.E & $P$-value & Estimate & S.E & $P$-value & Estimate & S.E & $P$-value \\
\hline c1 & & & & -0.0338 & 0.01127 & 0.0026 & 0.0139 & 0.00198 & $<0.0001$ \\
\hline c2 & & & & 0.5166 & 0.00219 & $<0.0001$ & 0.9699 & 0.00150 & $<0.0001$ \\
\hline c3 & 1.0144 & 0.00671 & $<0.0001$ & -0.0302 & 0.00047 & $<0.0001$ & -0.0020 & 0.00006 & $<0.0001$ \\
\hline c4 & 0.3661 & 0.01665 & $<0.0001$ & 0.1285 & 0.00508 & $<0.0001$ & 0.0068 & 0.00058 & $<0.0001$ \\
\hline c5 & & & & & & & 0.0002 & 0.00002 & $<0.0001$ \\
\hline c6 & 0.2653 & 0.01055 & $<0.0001$ & 0.1031 & 0.00094 & $<0.0001$ & 0.0057 & 0.00053 & $<0.0001$ \\
\hline c7 & & & & 0.0549 & 0.00628 & $<0.0001$ & & & \\
\hline c8 & & & & -0.0004 & 0.00011 & 0.0003 & -0.0001 & 0.00002 & $<0.0001$ \\
\hline c9 & -0.0011 & 0.00029 & $<0.0001$ & -0.0004 & 0.00008 & $<0.0001$ & -0.0002 & 0.00001 & $<0.0001$ \\
\hline c10 & & & & & & & 0.0006 & 0.00017 & $<0.0001$ \\
\hline
\end{tabular}


Table 5 (on next page)

Fixed effects parameter estimates and standard errors for each section of the knot trajectory model given by equation (5)

Section 1: typically increasing trajectory (years 0 to 50 ), Section 2: typically decreasing trajectory (years $>50$ ) 


\begin{tabular}{crrrrrr}
\hline & \multicolumn{3}{c}{ Section 1 } & \multicolumn{3}{c}{ Section 2 } \\
\hline Parameter & Estimate & \multicolumn{1}{c}{ S.E } & $\boldsymbol{P}$-value & Estimate & \multicolumn{1}{c}{ S.E } & \multicolumn{1}{c}{$\boldsymbol{P}$-value } \\
\hline $\mathrm{d}_{1}$ & -0.2753 & 0.03019 & $<0.0001$ & 0.0188 & 0.00447 & $<0.0001$ \\
$\mathrm{~d}_{2}$ & -0.0027 & 0.00025 & $<0.0001$ & -0.0003 & 0.00014 & 0.0328 \\
$\mathrm{~d}_{3}$ & 0.1864 & 0.00236 & $<0.0001$ & 0.9719 & 0.00391 & $<0.0001$ \\
$\mathrm{~d}_{4}$ & -0.0039 & 0.00012 & $<0.0001$ & 0.0002 & 0.00004 & $<0.0001$ \\
$\mathrm{~d}_{5}$ & 0.1294 & 0.00097 & $<0.0001$ & -0.0357 & 0.00255 & $<0.0001$ \\
$\mathrm{~d}_{6}$ & 0.2498 & 0.00927 & $<0.0001$ & -0.0033 & 0.00149 & 0.0252 \\
$\mathrm{~d}_{7}$ & 0.0064 & 0.00211 & 0.0024 & & & \\
$\mathrm{~d}_{8}$ & 0.0036 & 0.00015 & $<0.0001$ & & & \\
$\mathrm{~d}_{9}$ & 0.0009 & 0.00009 & $<0.0001$ & 0.0001 & 0.00004 & 0.0074 \\
\hline
\end{tabular}

3

4 


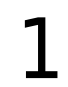

The knot extraction process.

A) Extraction of the position and diameter of each knot profile on CT scanning images using the ImageJ Java plug-in 'Gourmand' and B) reconstruction of the 3D geometry of each knot using the software "Bil3D"
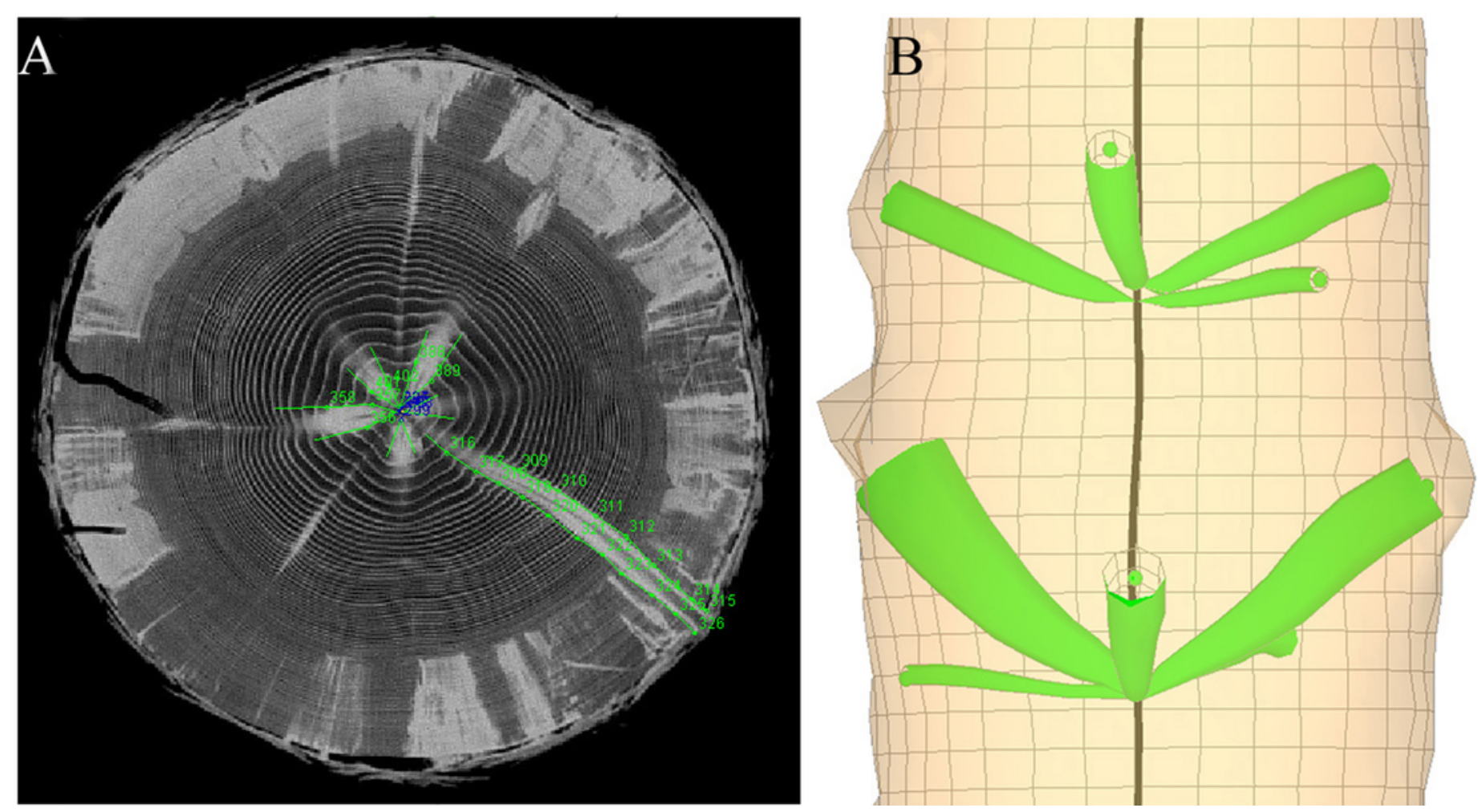
2

Inferring ring width at the location of a knot

A) interpolation of the rings between the two discs to reconstruct the $\log$ and $B$ ) selection of the two cardinal directions bordering the knot to reconstruct the ring widths along the knot profile
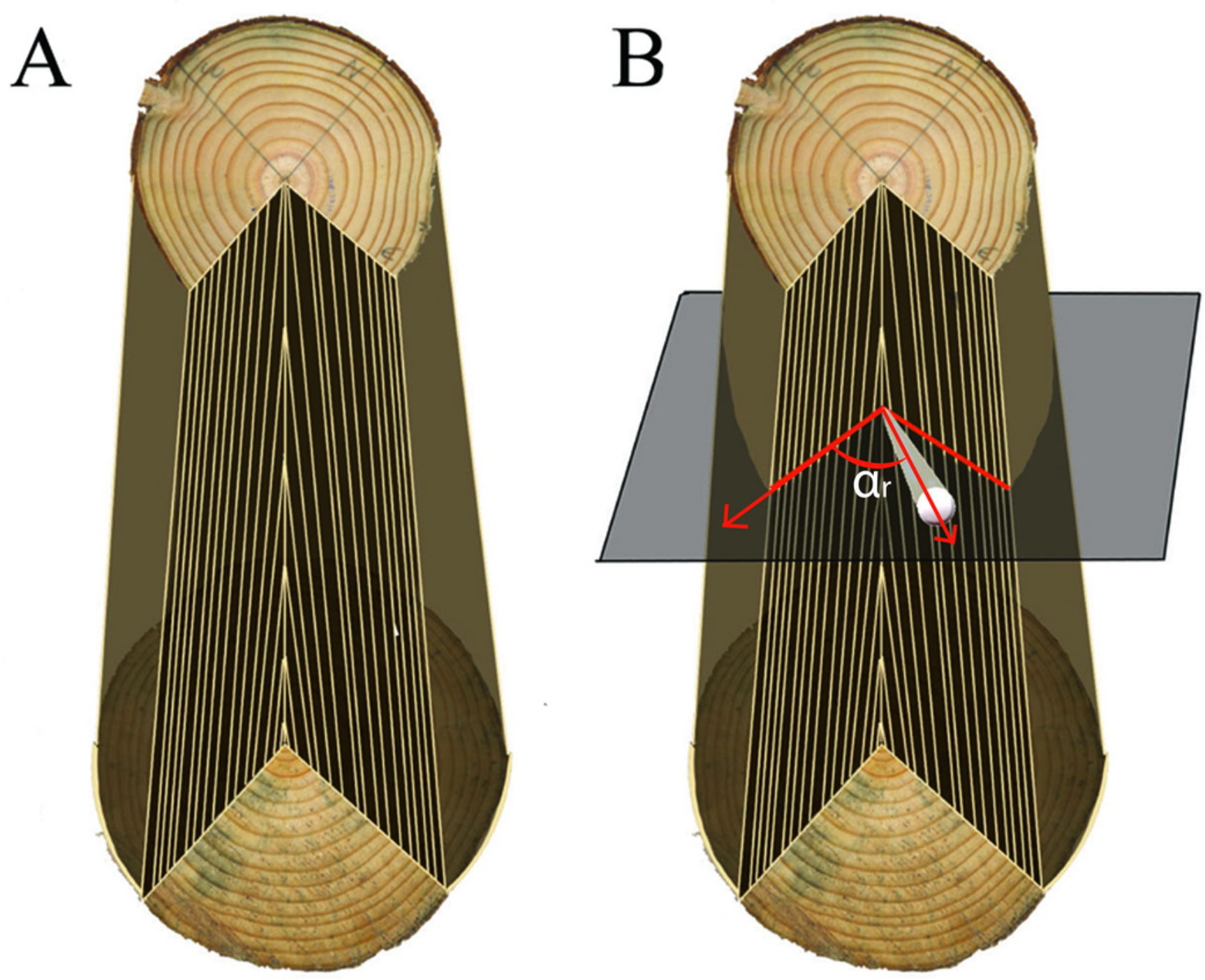
3

Inferring knot annual increments

A) example of ring width deformations around a knot; B) extraction of the annual knot data
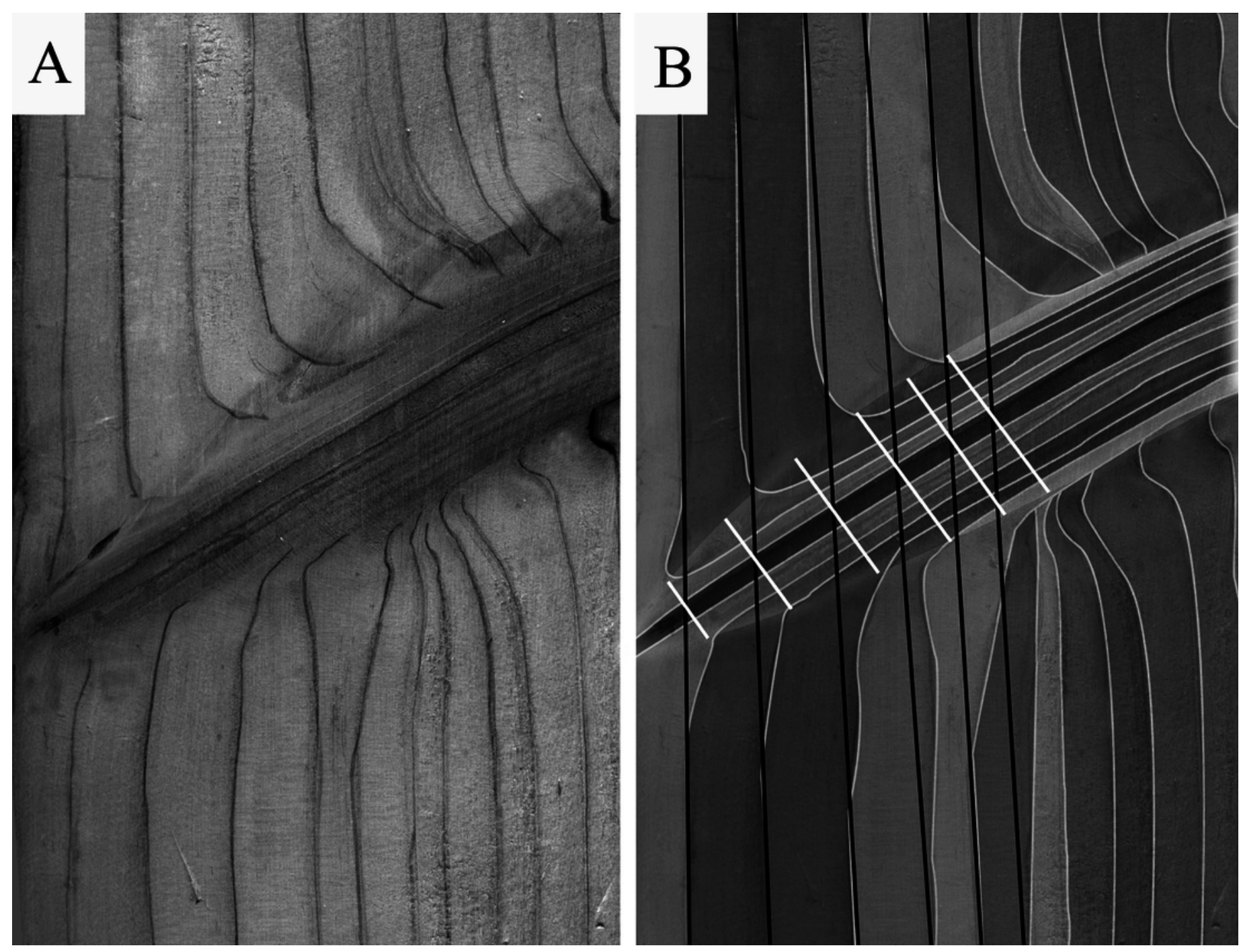
4

Distributions of annual increments in diameter $\left(\Delta \mathrm{D}_{\mathrm{t}}\right)$ and trajectory $\left(\Delta \mathrm{Z}_{\mathrm{t}}\right)$ of the knot against annual ring number from the stem's pith

The grey line indicates the median of all observations for a given ring number. Contours provide the distribution quantiles around the median
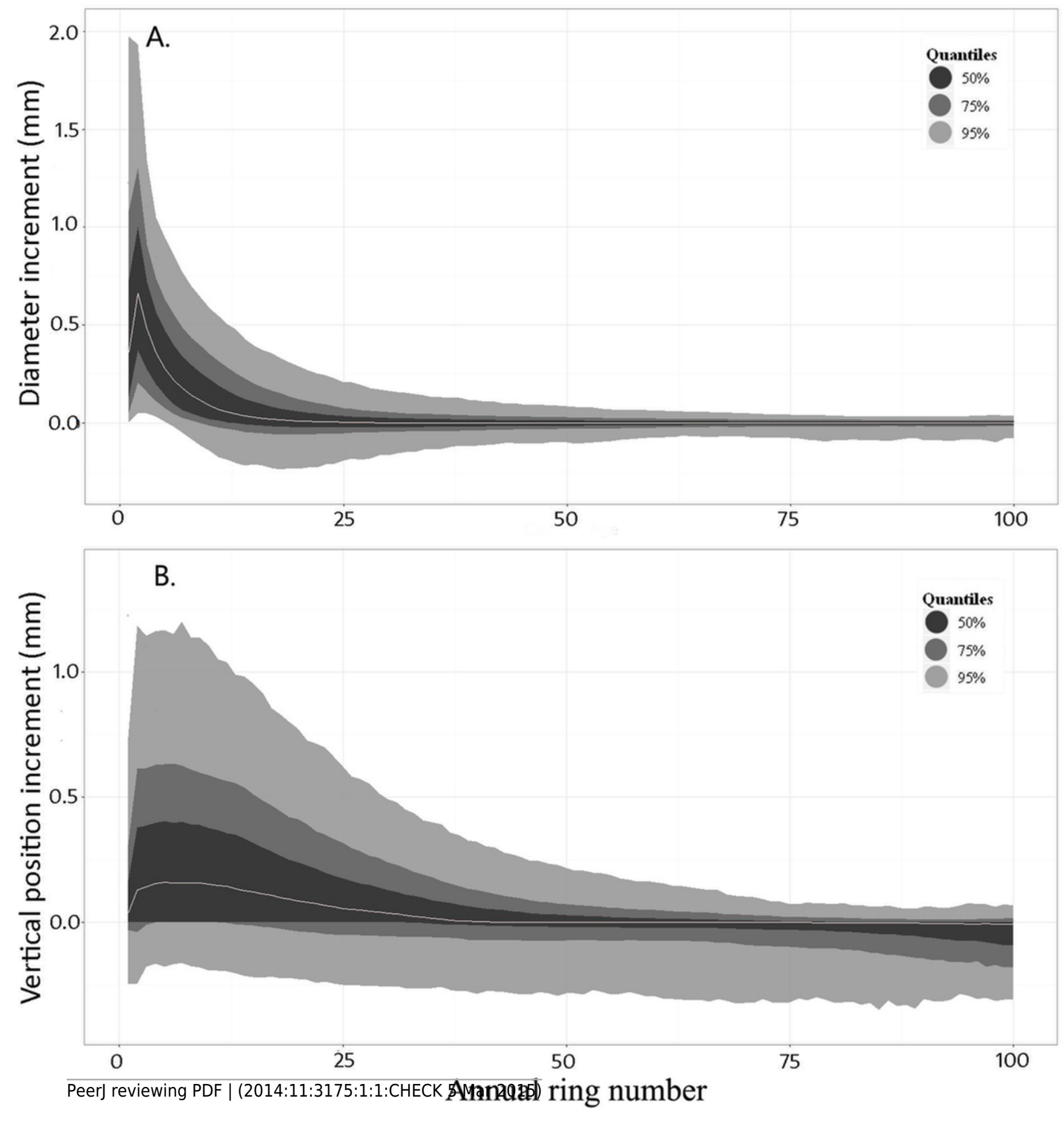


\section{5}

Scatterplots showing the evolution of KSR (total annual knot area increment/stem increment at $1.3 \mathrm{~m}$ ) with tree age

Time series do not start at age 0 because $H D_{t}$ assessments start when the stem has reached a height of $1.3 \mathrm{~m}$. Points = observed values; red lines = model predictions (Equation 2; Table 3 ). Horizontal red line shows an equality between the total annual knot increment and the stem increment at $1.3 \mathrm{~m}(\mathrm{KSR}=1)$

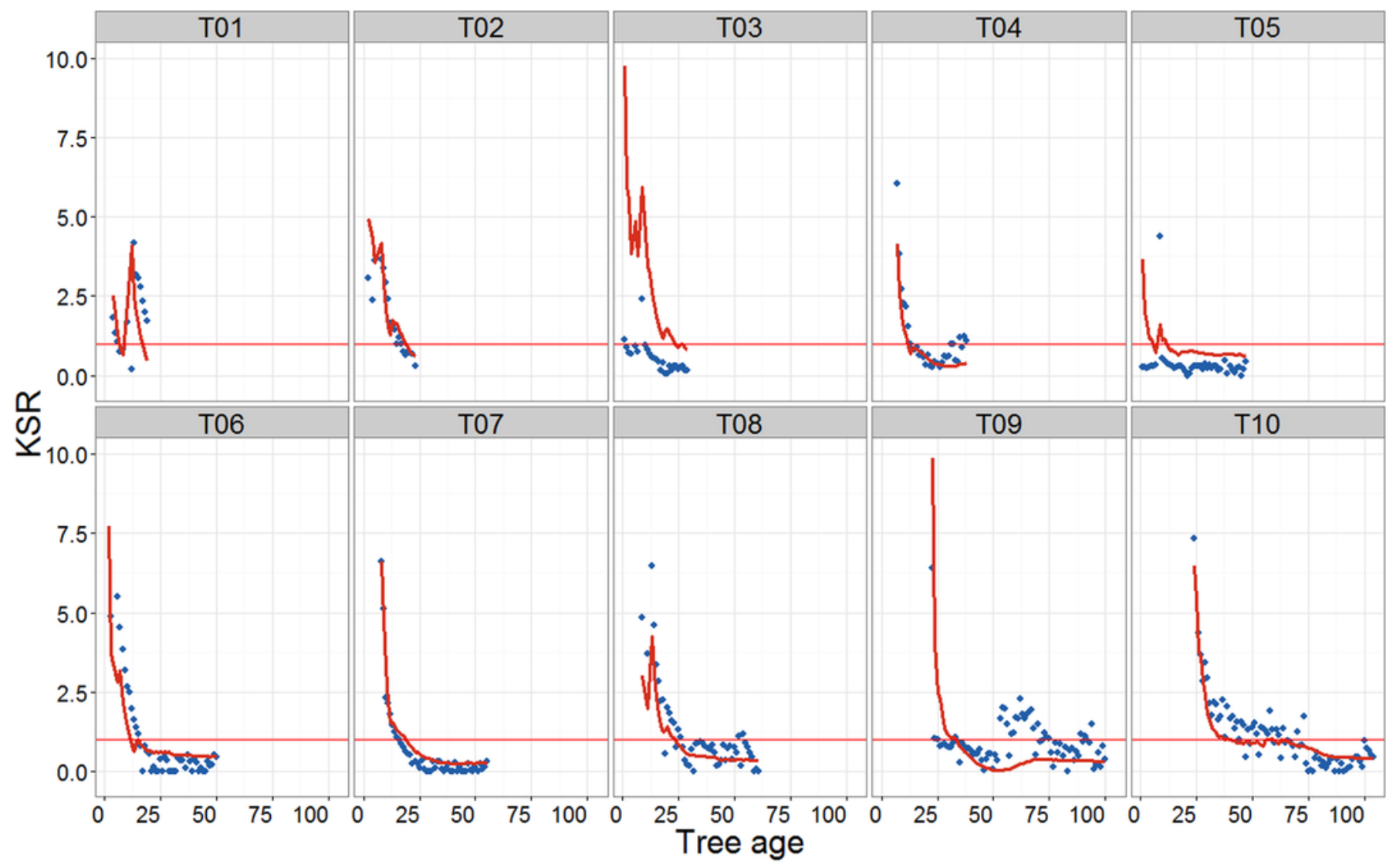


6

Scatterplots of observed $\mathrm{KSR}_{\mathrm{t}} \mathrm{vs}$. $\mathrm{HD}_{\mathrm{t}}$ in each sample tree for cambial ages 5, 15, 25 and 35 at breast height

The linear regressions fitted though the points show a positive correlation between the two variables for all ages. The shaded areas represent the standard errors
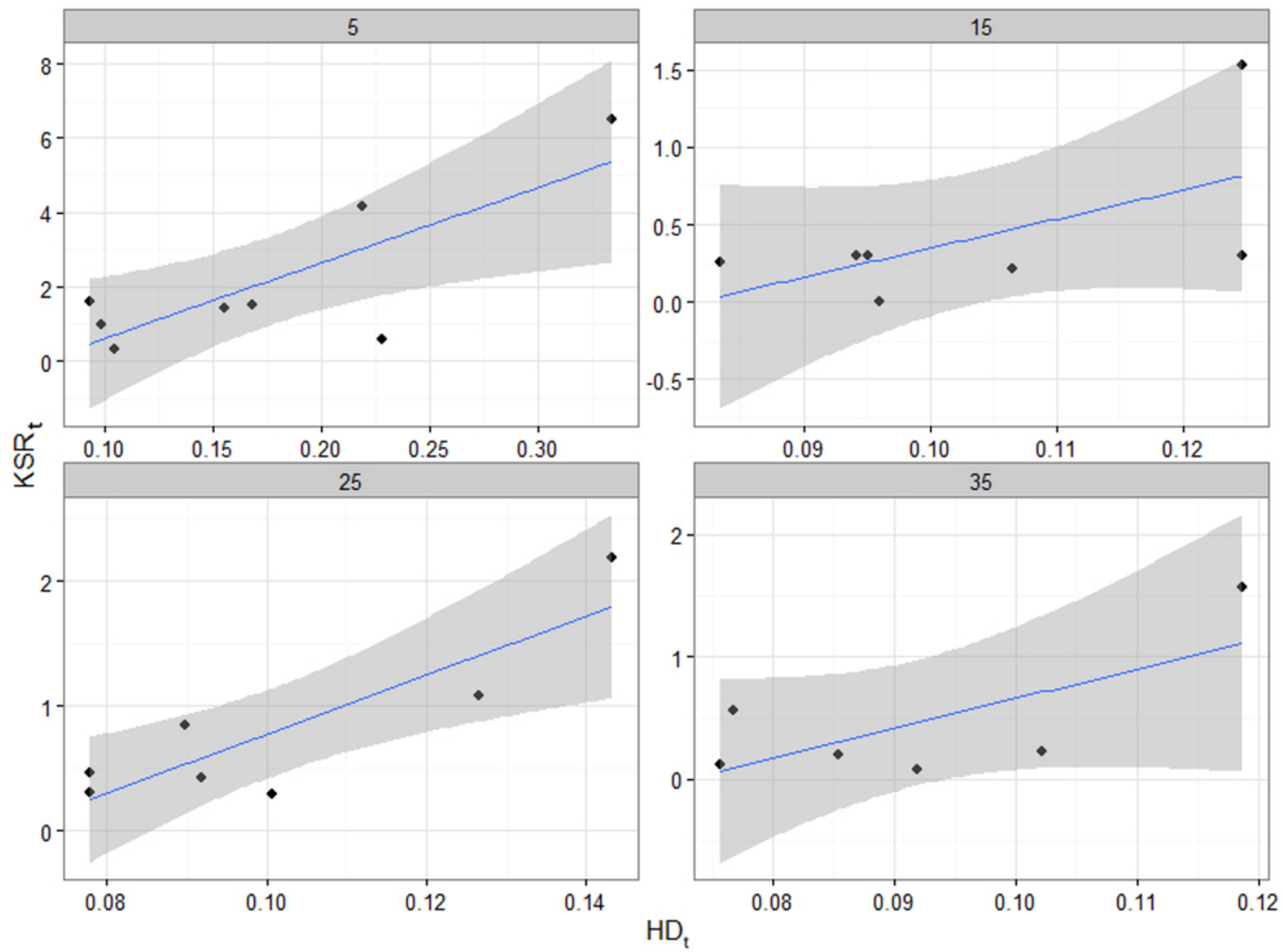
7

3D reconstruction of sections of two stems showing deviation of the pith related to possible stem breakage 
PeerJ Reviewing Manuscript

\section{T01}

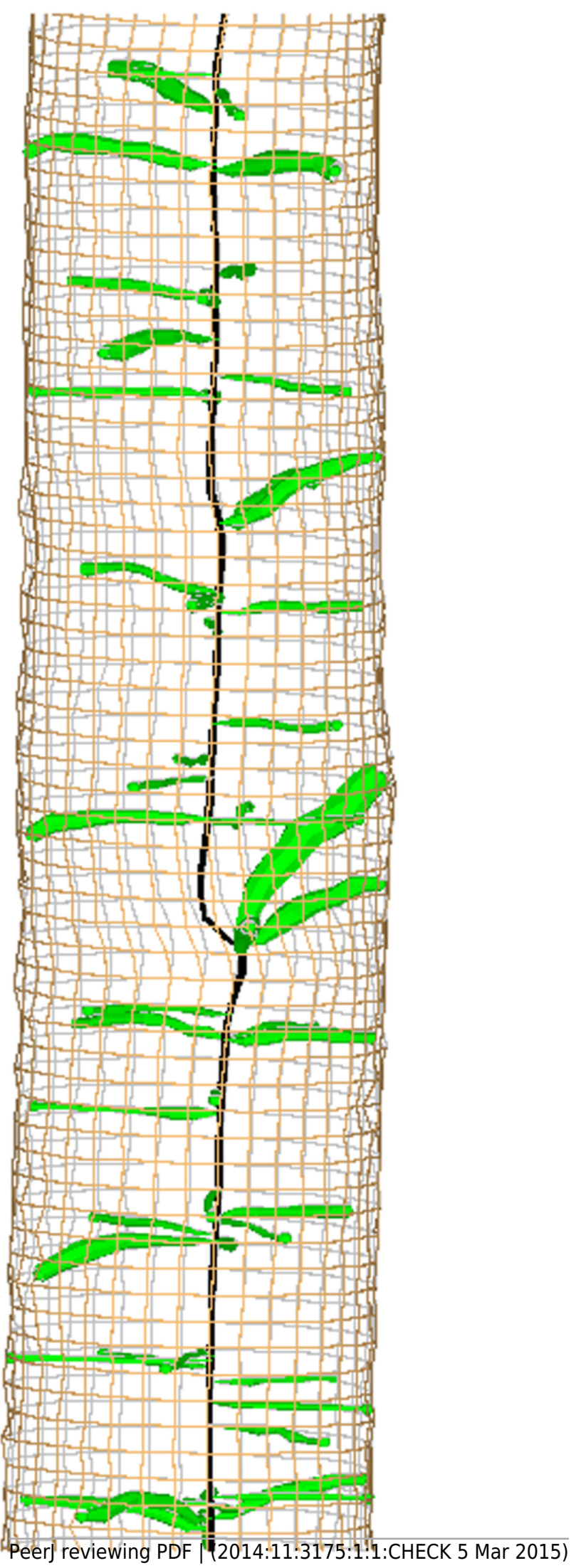

T09

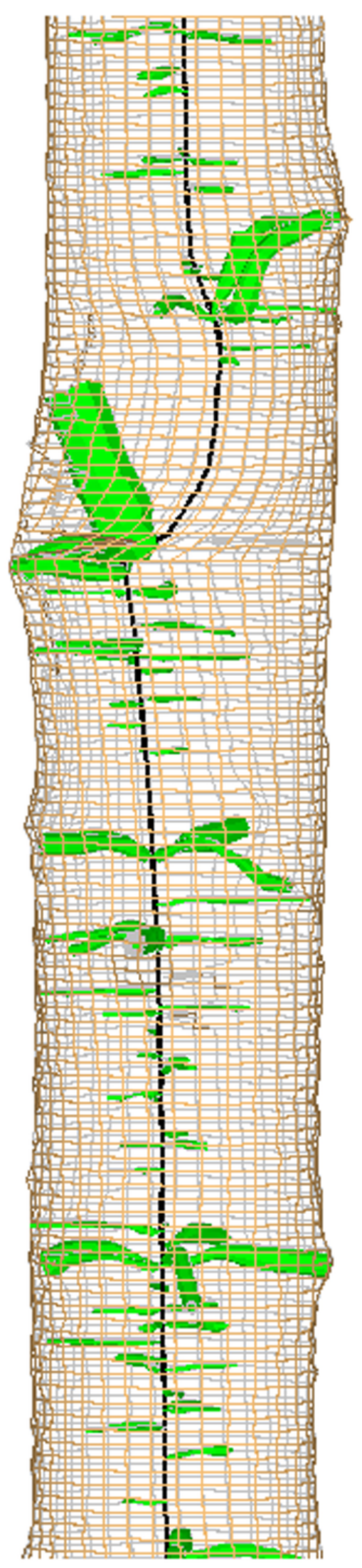


8

Distribution of the residuals (sorted by quantiles) against ring number when the model was applied to the evaluation dataset

A) Knot diameter (Equation 4, Table 4) and B) knot vertical position (Equation 5, Table 5). The grey line indicates the median of all observations for a given ring number. Contours provide the distribution around the median 


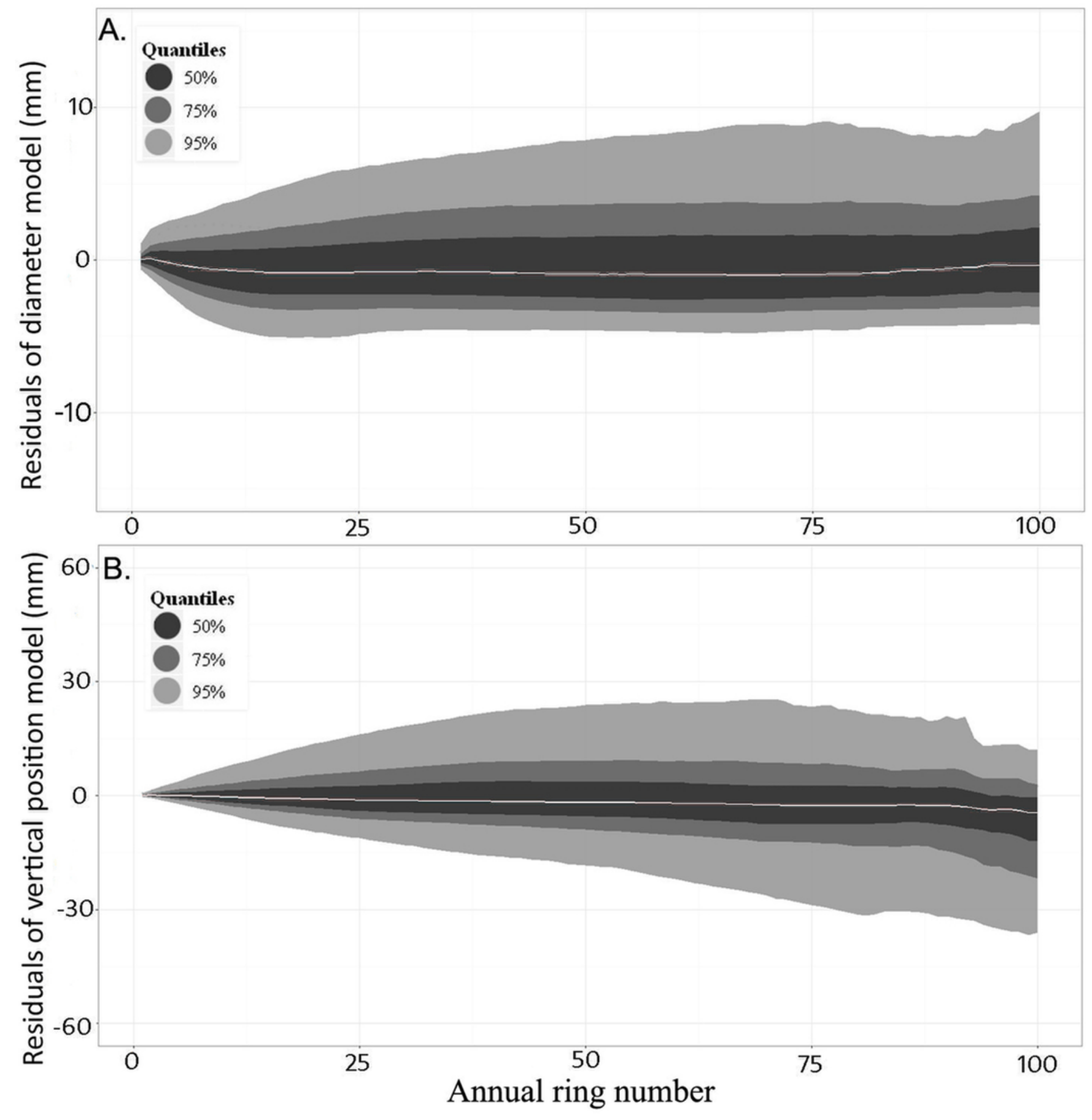


9

Simulations of a single knot from equations (4) and (5) at $6.1 \mathrm{~m}$ of the main stem.

Stem increments of tree T10 were used as the reference level for input parameters. A) Radial growth decreased by 50\%; B) Reference level and C) Radial growth increased by $50 \%$. Real height growth from tree T10 was used for all simulations. The knot was assumed to have died when diameter increments reached zero. Red: live section; Blue: dead section

A

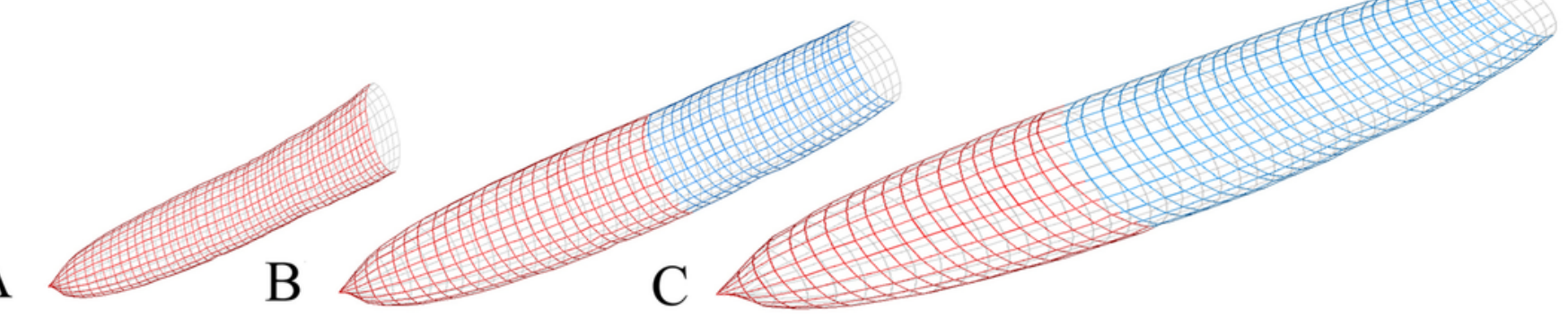




\section{0}

Reconstruction of a 1.5-m section from the base of the second log of tree T04 (i.e. at 2.5 $\mathrm{m}$ from the tree base)

A) Real knots extracted using the CT scanning data. B) Simulated knots using the known insertion point, azimuthal orientation around the stem, and year of occlusion 


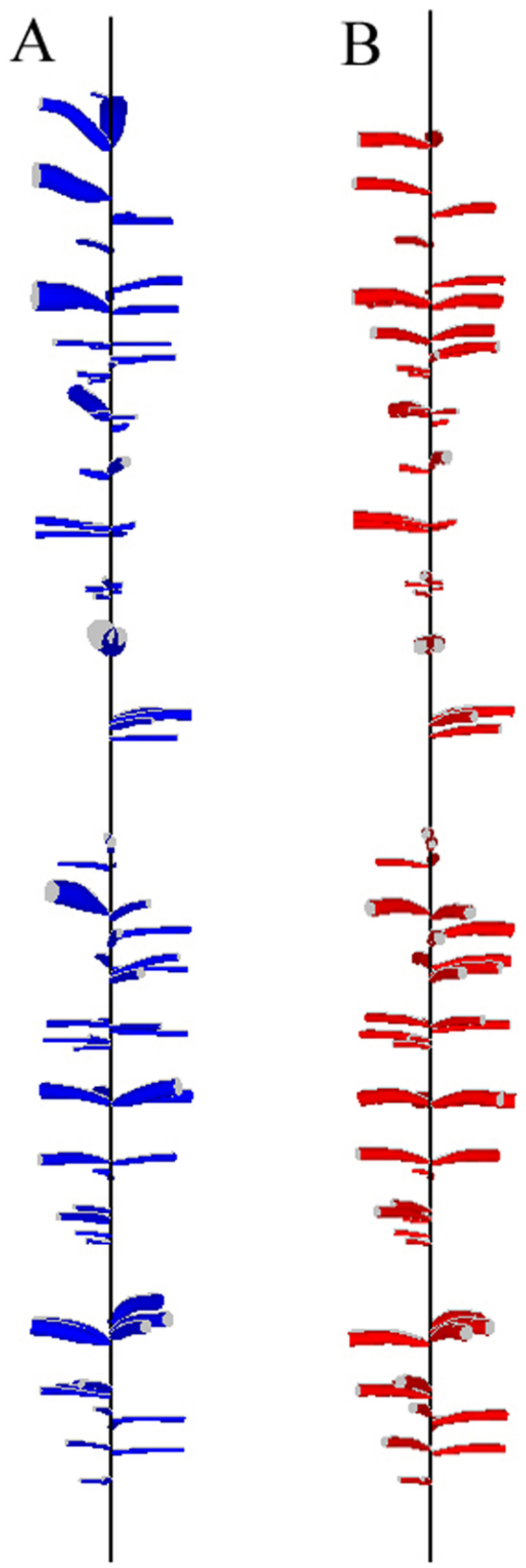

